\title{
Age-related Differences in Tumour Characteristics and Prognostic Factors for Disease Progression in Cutaneous Squamous Cell Carcinoma of the Head and Neck
}

Alet J. G. LEUS ${ }^{1}$, Marjolijn S. HAISMA ${ }^{1}$, Jorrit B. TERRA ${ }^{1}$, Gilles F. H. DIERCKS ${ }^{2}$, Marloes S. VAN KESTER ${ }^{1}$, Gyuri B. HALMOS ${ }^{3}$, Emöke RÁCZ ${ }^{1}$, Boukje A. C. VAN DIJK ${ }^{4,5}$ and Boudewijn E. C. PLAAT ${ }^{3}$

Departments of ${ }^{1}$ Dermatology, ${ }^{2}$ Pathology, ${ }^{3}$ Otorhinolaryngology, Head and Neck Surgery and ${ }^{4}$ Epidemiology, University of Groningen, University Medical Center Groningen, Groningen and ${ }^{5}$ Department of Research and Development, Netherlands Comprehensive Cancer Organisation (IKNL), Utrecht, The Netherlands

\begin{abstract}
Guidelines for cutaneous squamous cell carcinoma of the head and neck do not take the age of the patient into account, but instead assume equal tumour characteristics and prognostic factors for poor outcome in younger and elderly patients. The aim of this study was to compare tumour characteristics of younger ( $<75$ years) and elderly ( $\geq 75$ years) patients and identify age-specific risk factors for progression of disease, comprising local recurrence, nodal metastasis and distant metastasis. Patient and tumour characteristics were compared using $x^{2}$ or Fisher's exact tests. Multivariable competing risk analyses were performed to compare risk factors for progression of disease, incorporating the risk of dying before developing progression of disease. A total of 672 patients with primary cutaneous squamous cell carcinoma of the head and neck were retrospectively included. Larger tumour diameter, worse differentiation grade and deeper invasion were observed in older patients. In elderly patients, but not in younger patients, tumour diameter $\geq \mathbf{4 0} \mathbf{~ m m}$, moderate differentiation grade and an invasion depth $\geq 2 \mathrm{~mm}$ were independent risk factors for progression of disease.
\end{abstract}

Key words: cutaneous squamous cell carcinoma of the head and neck; ageing; metastasis; recurrence; disease progression; elderly.

Accepted Dec 22, 2021; Epub ahead of print Dec 22, 2021

Acta Derm Venereol 2022; 102: adv00652.

DOI: $10.2340 /$ actadv.v101.347

Corr: Alet J. G. Leus, Department of Dermatology, University Medical Center Groningen, Hanzeplein 1, NL-9700 RB Groningen. The Netherlands. E-mail: a.j.g.leus@umcg.nl

$\mathrm{C}$ utaneous squamous cell carcinoma (cSCC) is the second most common malignancy of the skin associated with metastatic disease, and the incidence is increasing (1-3). The most contributing risk factor for the development of cSCC is cumulative ultraviolet (UV) damage $(4,5)$. Therefore, cSCC is an increasing problem in the elderly population: the incidence of cSCC increases strongly with age worldwide $(6,7)$. The majority $(80-90 \%)$ of cSCCs is located in the head and neck region $(\mathrm{cSCCHN})(8,9)$. In most cases, the prognosis is excellent after excision of the primary tumour. However,

\section{SIGNIFICANCE}

Although the age of the patient is not taken into account in guidelines for cutaneous squamous cell carcinoma of the head and neck, the diagnosis and treatment of elderly patients can be challenging. Elderly patients often present with large tumours and, due to comorbidities or frailty, do not tolerate all treatment options. This study observed that characteristics of cutaneous squamous cell carcinoma of the head and neck might be age-specific and could influence treatment outcome. Therefore, the implementation of age in the guidelines for cutaneous squamous cell carcinoma of the head and neck could help treating physicians to identify patients with high-risk tumours and provide a more personalized treatment to prevent over- or under-treatment.

in patients with metastatic disease the long-term prognosis is poor $(3,10-13)$.

Guidelines for cSCC mention several prognostic factors for poor outcome, based on literature $(8,9)$. Based on these prognostic factors, cSCCs are divided into low-risk and high-risk tumours, which translates to a higher intensity of treatment and follow-up for patients with a high-risk cSCC. Age of the patient at diagnosis is not taken into account in these guidelines, instead they assume equal tumour properties in younger and elderly patients. Treatment choice and prognosis are not only determined by treatment guidelines and tumour characteristics, but also by patient factors (14). Since older patients often have comorbidities and are often frail, repeated or extensive surgical treatment should be considered carefully in these patients (14-16). This raises the question of whether existing treatment guidelines, based on tumour characteristics but lacking patients' characteristics, are equally applicable in both younger and older patients. Little is known about differences in prognostic tumour characteristics between younger and elderly patients.

This large retrospective study aimed to evaluate age-specific tumour characteristics in patients with cSCCHNs. A further aim was to identify age-specific prognostic factors for progression of disease. This could help treating physicians to adjust treatment and follow-up of cSCCHNs to the age of patients. 
Table I. Patient and tumour characteristics divided into age groups

\begin{tabular}{|c|c|c|c|c|}
\hline & $\begin{array}{l}\text { Total group } \\
(n=672)\end{array}$ & $\begin{array}{l}\text { Patients }<75 \text { years } \\
(n=316)\end{array}$ & $\begin{array}{l}\text { Patients } \geq 75 \text { years } \\
(n=356)\end{array}$ & $p$-value* \\
\hline Age, years, median (range) & $75(25-105)$ & $66(25-74)$ & $82(75-105)$ & $<0.001$ \\
\hline Sex, $n(\%)$ & & & & 0.959 \\
\hline Men & $443(65.9)$ & $208(65.8)$ & $235(66.0)$ & \\
\hline Women & $229(34.1)$ & $108(34.2)$ & $121(34.0)$ & \\
\hline Comorbidities*, $n(\%)$ & & & & $<0.001$ \\
\hline None & $157(23.4)$ & $108(34.2)$ & $49(13.8)$ & \\
\hline Mild & $214(31.8)$ & $102(32.3)$ & $112(31.5)$ & \\
\hline Moderate & $202(30.1)$ & $61(19.3)$ & $141(39.6)$ & \\
\hline Severe & $91(13.5)$ & $44(13.9)$ & $47(13.2)$ & \\
\hline Unknown & $8(1.2)$ & $1(0.3)$ & $7(2.0)$ & \\
\hline Immunosuppression, $n(\%)$ & $63(9.4)$ & $34(10.8)$ & $29(8.1)$ & 0.256 \\
\hline ECOG performance score, $n(\%)$ & & & & $<0.001$ \\
\hline $0-1$ & $466(69.4)$ & $259(82)$ & $207(58.1)$ & \\
\hline $2-4$ & $64(9.5)$ & $7(2.2)$ & $57(16.0)$ & \\
\hline Unknown & $142(21.1)$ & $50(15.8)$ & $92(25.8)$ & \\
\hline Number of cSCCs, median (range), mean & $1(1-16), 1.27$ & $1(1-16), 1.30$ & $1(1-6), 1.24$ & 0.118 \\
\hline \multicolumn{5}{|l|}{ Tumour location, $n(\%)$} \\
\hline Forehead & $59(8.8)$ & $24(7.6)$ & $35(9.8)$ & 0.307 \\
\hline Temples & $71(10.6)$ & 25 (7.9) & $46(12.9)$ & 0.035 \\
\hline Periocular & $30(4.5)$ & $16(5.1)$ & $14(3.9)$ & 0.479 \\
\hline Cheek & $100(14.9)$ & $43(13.6)$ & $57(16.0)$ & 0.382 \\
\hline Nose bridge/tip & $58(8.6)$ & $38(12.0)$ & $20(5.6)$ & 0.003 \\
\hline Nostril & $19(2.8)$ & $16(5.1)$ & $3(0.8)$ & 0.001 \\
\hline Cutaneous upper lip & $2(0.3)$ & 0 & $2(0.6)$ & 0.501 \\
\hline Vermillion & $83(12.4)$ & $54(17.1)$ & $29(8.1)$ & $<0.001$ \\
\hline Cutaneous lower lip and chin & $3(0.4)$ & $2(0.6)$ & $1(0.3)$ & 0.603 \\
\hline Neck & $18(2.7)$ & $10(3.2)$ & $8(2.2)$ & 0.462 \\
\hline Ear & $133(19.8)$ & $49(15.5)$ & $84(23.6)$ & 0.009 \\
\hline Scalp & $83(12.4)$ & $29(9.2)$ & $54(15.2)$ & 0.018 \\
\hline Vestibulum nasi & $7(1.0)$ & $6(1.9)$ & $1(0.3)$ & 0.056 \\
\hline Ear canal & $6(0.9)$ & $4(1.3)$ & $2(0.6)$ & 0.428 \\
\hline Tumour diameter, $\mathrm{mm}, n(\%)$ & & & & $<0.001$ \\
\hline$<20$ & $517(76.9)$ & $270(85.4)$ & $247(69.4)$ & \\
\hline $20-39$ & $117(17.4)$ & $33(10.4)$ & $84(23.6)$ & \\
\hline$\geq 40$ & $34(5.1)$ & $12(3.8)$ & $22(6.2)$ & \\
\hline Unknown & $4(0.6)$ & $1(0.3)$ & $3(0.8)$ & \\
\hline Tumour differentiation, $n(\%)$ & & & & 0.063 \\
\hline Well & $288(42.9)$ & $150(47.5)$ & $138(38.8)$ & 0.025 \\
\hline Moderate & $329(49.0)$ & $145(45.9)$ & $184(51.7)$ & 0.124 \\
\hline Poor & $54(8.0)$ & $21(6.6)$ & $33(9.3)$ & 0.208 \\
\hline Unknown & $1(0.1)$ & 0 & $1(0.3)$ & - \\
\hline Invasion depth, $\mathrm{mm}, n(\%)$ & & & & 0.017 \\
\hline$<2$ & $284(42.3)$ & $151(47.8)$ & $133(37.4)$ & \\
\hline $2-6$ & $313(46.6)$ & $130(41.1)$ & $183(51.4)$ & \\
\hline$>6$ & $70(10.4)$ & $32(10.1)$ & $38(10.7)$ & \\
\hline Unknown & $5(0.7)$ & $3(0.9)$ & $2(0.6)$ & \\
\hline Perineural invasion, $n(\%)$ & $60(8.9)$ & $26(8.2)$ & $34(9.6)$ & 0.548 \\
\hline Vascular invasion, $n(\%)$ & $15(2.2)$ & $6(1.9)$ & $9(2.5)$ & 0.581 \\
\hline \multicolumn{5}{|l|}{ Extradermal invasion, $n(\%)$} \\
\hline Invasion in muscle & $27(4.0)$ & $15(4.7)$ & $12(3.4)$ & 0.365 \\
\hline Invasion in cartilage & $19(2.8)$ & $6(1.9)$ & $13(3.7)$ & 0.171 \\
\hline Invasion in bone & $3(0.4)$ & $3(0.9)$ & 0 & 0.103 \\
\hline Invasion in parotid & $1(0.1)$ & 0 & $1(0.3)$ & $>0.999$ \\
\hline Unknown & $8(1.2)$ & $2(0.6)$ & $6(1.7)$ & 0.293 \\
\hline \multicolumn{5}{|l|}{ T-stage (AJCC 8), $n(\%)$} \\
\hline $\mathrm{T} 1$ & $457(68.0)$ & $239(75.6)$ & $218(61.2)$ & $<0.001$ \\
\hline $\mathrm{T} 2$ & $75(11.2)$ & $21(6.6)$ & $54(15.2)$ & $<0.001$ \\
\hline T3 & $133(19.8)$ & $52(16.5)$ & $81(22.8)$ & 0.041 \\
\hline $\mathrm{T} 4 \mathrm{a}$ & $3(0.4)$ & $3(0.9)$ & 0 & 0.103 \\
\hline Unknown & $4(0.6)$ & $1(0.3)$ & $3(0.8)$ & 0.627 \\
\hline \multicolumn{5}{|l|}{ Treatment modality, $n(\%)$} \\
\hline Surgical monotherapy & $525(78.1)$ & $253(80.1)$ & $272(76.4)$ & 0.252 \\
\hline Radiation monotherapy & $61(9.1)$ & $24(7.6)$ & $37(10.4)$ & 0.208 \\
\hline Surgery and radiotherapy & $73(10.9)$ & $35(11.1)$ & $38(10.7)$ & 0.867 \\
\hline None/palliative/other/unknown & $13(1.9)$ & $4(1.3)$ & $9(2.5)$ & 0.236 \\
\hline Surgical margin, $\mathrm{mm}, n(\%)$ & & & & 0.597 \\
\hline$<2$ & $262(39.0)$ & $116(36.7)$ & $146(41.0)$ & \\
\hline $2-5$ & $183(27.2)$ & $77(24.4)$ & $106(29.8)$ & \\
\hline$>5$ & $82(12.2)$ & $40(12.7)$ & $42(11.8)$ & \\
\hline Not treated surgically/no tumour found after biopsy/unknown & $145(21.6)$ & $83(26.3)$ & $62(17.4)$ & \\
\hline Local recurrence, $n(\%)$ & $53(7.9)$ & $23(7.3)$ & $30(8.4)$ & 0.581 \\
\hline Lymph node metastasis, $n(\%)$ & $44(6.5)$ & $11(3.5)$ & $33(9.3)$ & 0.002 \\
\hline Distant metastasis, $n(\%)$ & $6(0.9)$ & 0 & $6(1.7)$ & 0.032 \\
\hline Progression of disease, $n(\%)^{\mathrm{b}}$ & $83(12.4)$ & $30(9.5)$ & $53(14.9)$ & 0.034 \\
\hline
\end{tabular}

${ }^{\mathrm{a}} \mathrm{T} 4 \mathrm{a}(n=2)$ and T4b $(n=1)$ were analysed as 1 category. ${ }^{\mathrm{b}}$ Progression of disease comprises local recurrence, nodal metastasis and distant metastasis. $* p$-value of $x^{2}$ test (or Fisher's exact test in the case of an expected count less than 5 in $20 \%$ of the cells or more) between age $<75$ and age $\geq 75$ years. Age at diagnosis and number of cSCCHNs per patient did not have a normal distribution and were compared with a Mann-Whitney $U$ test.

The category "unknown" was not included in the analyses, except for the variables Eastern Cooperative Oncology Group performance score, extradermal invasion, American Joint Committee on Cancer $8^{\text {th }}$ edition (AJCC 8) tumour stage and treatment modality.

Perineural invasion was $\geq 0.1 \mathrm{~mm}$ in calibre in all cases.

cSCC: cutaneous squamous cell carcinoma; NS: not significant. Significant $p$-values are shown in bold. 


\section{MATERIALS AND METHODS}

This retrospective study included patients with histologically proven primary cSCCHN, diagnosed or treated in the University Medical Center Groningen (UMCG), a tertiary care academic hospital in the Netherlands, from 1 January 2000 until 1 January 2014. Patients with a history of organ transplant or chronic lymphatic leukaemia (CLL) were excluded from analysis, in order to prevent overestimation of number and aggressiveness of tumours. Poor outcome was defined as progression of disease (POD), comprising local recurrence, nodal metastases and distant metastases. Patients with POD within 1 month or death within 1 month were not included for analysis, in order to prevent residual disease being interpreted as disease progression. Patients were divided into 2 age groups; patients $<75$ and patients $\geq 75$ years of age, based on the median age in our cohort and the classification of "middle-old" by the National Institute on Aging (17).

Patient, tumour and treatment characteristics were extracted from the medical records. Patient-related data included sex, age at the time of histological diagnosis, comorbidities indexed by the Adult Comorbidity Evaluation-27 (ACE-27), performance score indexed by the Eastern Cooperative Oncology Group (ECOG) and presence of immunocompromisation. Histopathological characteristics were derived from pathology reports, and included tumour differentiation, invasion depth, presence of perineural or vascular invasion and histopathological excision margins. Re-assessment of the histopathology was performed by a dermato-pathologist (GD) if data were missing. Tumours were restaged according to the $8^{\text {th }}$ edition of the American Joint Committee on Cancer Staging Manual (AJCC8) (18). The number of cSCCs was defined as the total number of primary cSCCs including the current one. Follow-up time was defined as the time between diagnosis and last follow-up visit or death.

Statistical analyses were performed using SPSS (v.22.0; SPSS Inc., Chicago, IL, USA) and STATA (v. 14.2; StataCorp). Patient and tumour characteristics were summarized using descriptive statistics and compared using a $\chi^{2}$ or Fisher's exact test. Correlation analyses were performed using Pearson correlation for continuous variables and Spearman correlation for categorical variables. Due to our elderly population, competing risk analyses were performed to account for the risk of dying before developing poor outcome, and visualized with cumulative incidence function (CIF) curves for POD per age group. Univariable and multivariable competing risk analyses were performed to compare prognostic factors for POD between the 2 age groups. Death was defined as a competing event. Due to small numbers, the category "unknown" in categorical variables was not selected for analysis. In the AJCC 8 variable, stages T4a and T4b were analysed as 1 group. The proportional hazard assumption was assessed by adding a time-varying covariate to check whether each variable interacted with time. The Wald test was used to test the significance of categorical variables in the case of heterogeneity in significance of covariates. Only significant variables were included in the multivariable model. All analyses were performed at the level of the patient; in the case of multiple tumours per patient the tumour with the highest stage was selected, in the case of equal stages the tumour that developed first within the inclusion period was selected. $p$-values $<0.05$ were considered statistically significant.

\section{RESULTS}

A total of 770 patients with $1,116 \mathrm{cSCCHNs}$ could be identified. Exclusion of patients

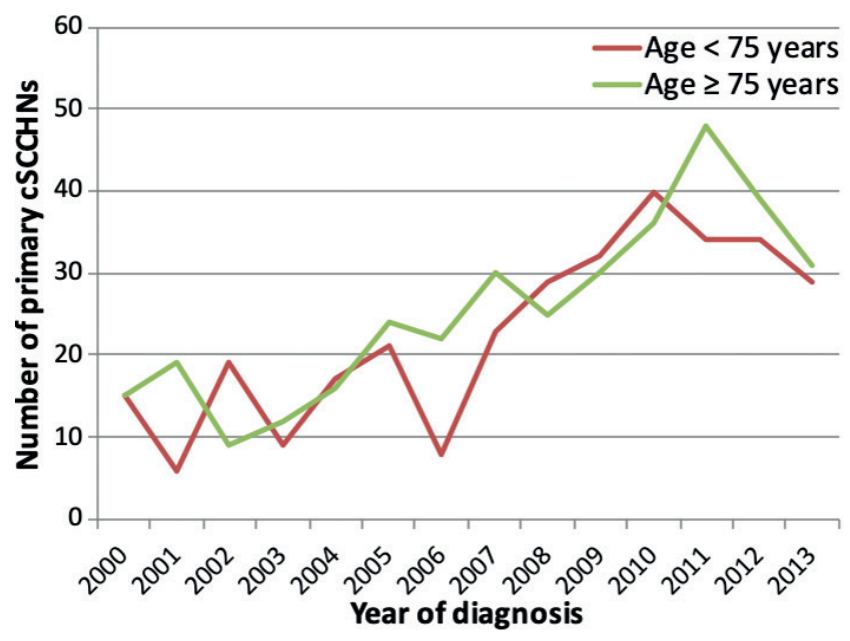

Fig. 1. Number of primary cutaneous squamous cell carcinoma of the head and neck (cSCCHN) per year, by age group.

with a history of organ transplant $(n=65), \operatorname{CLL}(n=17)$ and progression of disease or death within 1 month after tumour diagnosis $(n=16)$ left a total of 672 patients with 845 tumours to be analysed. Patient and tumour characteristics for the total patient group and the age groups below 75 years old and 75 years or older are shown in Table I. The median age of the patients was 75 years (range $25-105$ years), and $65.9 \%$ of patients were men. Most tumours were staged as T1 (68.0\%) and the most frequent treatment was surgery as monotherapy (78.1\%). The number of patients with cSCCHN increased over the years for both younger and elderly patients, with an

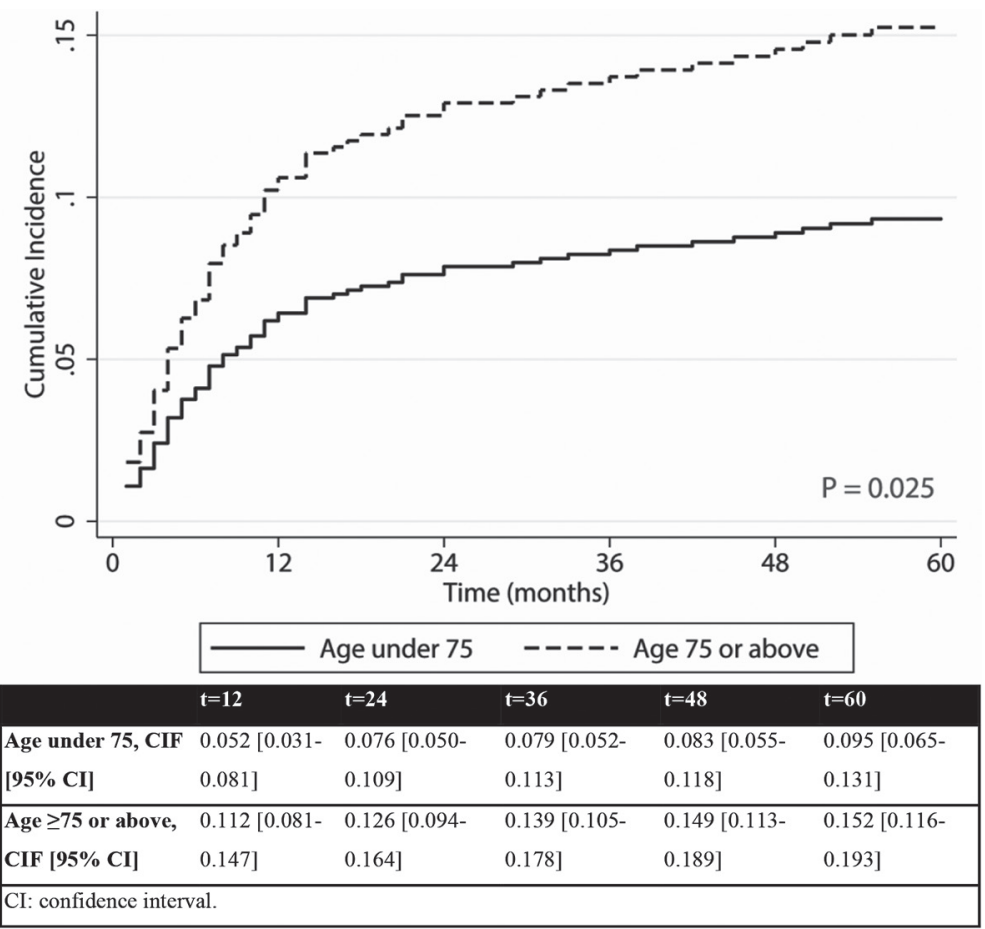

Fig. 2. Cumulative incidence function (CIF) curves of progression of disease (POD), comprising local recurrence, nodal metastasis and distant metastasis within $\mathbf{6 0}$ months per age group with death as competing risk. 
increase from 2000 to 2013 of $200 \%$ in the total group, $193 \%$ in the younger group, and $207 \%$ in the elderly group (Fig. 1). Elderly patients had tumours with more high-risk characteristics, such as larger tumour diameter $(p<0.001)$, worse differentiation grade $(p=0.011)$ and deeper tumour invasion $(p=0.034)$, compared with younger patients. Furthermore, tumour location was different between the 2 age groups $(p<0.001)$ with more tumours on the scalp $(p<0.001)$ and ear $(p=0.018)$ in the elderly patients, and more tumours on the nose $(p<0.001)$ in the younger patients. Lymph node metastasis $(p=0.020)$ and POD $(p=0.038)$ were observed more frequently in the elderly patients.

A correlation was found between age and tumour diameter $(p<0.001)$, age and differentiation grade $(p=0.047)$ and between comorbidity and performance score $(p<0.001)$. No correlation was found between age and invasion depth, age and localization of the tumour, age and perineural invasion, and age and surgical margin.

Competing risk analysis for POD showed a total of 80 patients with the event POD and 201 patients with

Table II. univariable and multivariable competing risk analysis for POD within 60 months with death as a competing event in the total patient group $(n=672)$

\begin{tabular}{|c|c|c|c|c|}
\hline \multirow[b]{2}{*}{ Characteristic } & \multicolumn{2}{|l|}{ Univariable model } & \multicolumn{2}{|l|}{ Multivariable model } \\
\hline & SHR $[95 \% \mathrm{CI}]$ & $p$-value & SHR $(95 \% \mathrm{CI})$ & $p$-value \\
\hline \multicolumn{5}{|l|}{ Age } \\
\hline$<75$ years & 1 (reference) & & 1 (reference) & \\
\hline$\geq 75$ years & 1.69 [1.07-2.67] & 0.025 & $1.58[0.86-2.88]$ & 0.139 \\
\hline \multicolumn{5}{|l|}{ Sex } \\
\hline Men & 1 (reference) & & & \\
\hline Women & $0.64[0.38-1.06]$ & 0.080 & & \\
\hline \multicolumn{5}{|c|}{ Immunosuppression } \\
\hline Yes & $0.61[0.25-1.50]$ & 0.286 & & \\
\hline No & 1 (reference) & & & \\
\hline \multicolumn{5}{|l|}{ Comorbidities $^{a}$} \\
\hline None & 1 (reference) & & & \\
\hline Mild & $0.85[0.45-1.62]$ & 0.620 & & \\
\hline Moderate & $1.16[0.63-2.13]$ & 0.624 & & \\
\hline Severe & $1.53[0.77-3.07]$ & 0.228 & & \\
\hline \multicolumn{5}{|c|}{ Tumour diameter } \\
\hline$<20 \mathrm{~mm}$ & 1 (reference) & & 1 (reference) & \\
\hline 20-39 mm & $3.14[1.93-5.10]$ & $<0.001$ & $1.13[0.54-2.35]$ & 0.751 \\
\hline$\geq 40 \mathrm{~mm}$ & $3.76[1.82-7.76]$ & $<0.001$ & $2.19[0.92-5.24]$ & 0.078 \\
\hline \multicolumn{5}{|c|}{ Tumour differentiation } \\
\hline Well & 1 (reference) & & 1 (reference) & \\
\hline Moderate & 1.99 [1.17-3.37] & 0.011 & $2.89[1.41-5.96]$ & 0.004 \\
\hline Poor & $5.42[2.86-10.25]$ & $<0.001$ & $6.01[2.56-14.10]$ & $<0.001$ \\
\hline \multicolumn{5}{|l|}{ Invasion depth } \\
\hline$<2 \mathrm{~mm}$ & 1 (reference) & & 1 (reference) & \\
\hline $2-6 \mathrm{~mm}$ & $4.11[2.14-7.91]$ & $<0.001$ & $2.91[1.26-6.74]$ & 0.012 \\
\hline$>6 \mathrm{~mm}$ & 9.15 [4.43-18.93] & $<0.001$ & $5.49[1.97-15.31]$ & 0.001 \\
\hline \multicolumn{5}{|c|}{ Perineural invasion } \\
\hline Yes & $3.91[2.36-6.48]$ & $<0.001$ & $1.47[0.72-3.02]$ & 0.291 \\
\hline No & 1 (reference) & & 1 (reference) & \\
\hline \multicolumn{5}{|c|}{ Vascular invasion } \\
\hline Yes & $2.52[0.89-7.10]$ & 0.081 & & \\
\hline No & 1 (reference) & & & \\
\hline \multicolumn{5}{|c|}{ Surgical margin } \\
\hline$<2 \mathrm{~mm}$ & 1 (reference) & & 1 (reference) & \\
\hline$\geq 2 \mathrm{~mm}$ & $0.26[0.15-0.47]$ & $<0.001$ & $0.51[0.28-0.93]$ & 0.027 \\
\hline
\end{tabular}

${ }^{\mathrm{a} C o m o r b i d i t i e s ~ w e r e ~ i n d e x e d ~ b y ~ t h e ~ A d u l t ~ C o m o r b i d i t y ~ E v a l u a t i o n-27 ~(A C E-27) . ~}$ $p$-value calculated by Wald test.

95\% CI: 95\% confidence interval; POD: progression of disease, comprising local recurrence, nodal metastasis and distant metastasis; SHR: subhazard ratio. Significant $p$-values are shown in bold. the competing event death at 60 months. Three patients developed POD after 60 months. Fig. 2 shows the CIF curves for POD with death as competing event for both age groups, including $95 \%$ confidence intervals $(95 \% \mathrm{CI})$ per time-point. Patients aged 75 years or above showed a higher incidence of POD within 60 months compared with the younger group ( $p=0.025)$. Results of the univariable and multivariable competing risk analyses for the total patient group are shown in Table II. Independent risk factors for POD within 60 months for the total patient group were moderate or poor differentiation grade, invasion depth of $2 \mathrm{~mm}$ or more, and a closer surgical margin. Age was not found to be an independent risk factor for POD.

Univariable and multivariable competing risk analyses were also performed for the 2 age groups separately (Tables III and IV). An independent risk factor for POD for both age groups was poor differentiation grade. A closer surgical margin was an independent risk factor in the younger group, but not in patients older than 75 years. In elderly patients, but not in younger patients, tumour diameter $\geq 40 \mathrm{~mm}$, moderate differentiation grade and an invasion depth of $\geq 2 \mathrm{~mm}$ were independent prognostic factors for POD.

Table III. Univariable and multivariable competing risk analysis for POD within 60 months in the patient group aged $<75$ years $(n=316)$

\begin{tabular}{|c|c|c|c|c|}
\hline \multirow[b]{2}{*}{ Characteristics } & \multicolumn{2}{|l|}{ Univariable model } & \multicolumn{2}{|l|}{ Multivariable model } \\
\hline & SHR $[95 \% \mathrm{CI}]$ & $p$-value & SHR $[95 \% \mathrm{CI}]$ & $p$-value \\
\hline \multicolumn{5}{|l|}{ Sex } \\
\hline Men & 1 (reference) & & & \\
\hline Women & $0.51[0.21-1.24]$ & 0.138 & & \\
\hline \multicolumn{5}{|c|}{ Immunosuppression } \\
\hline Yes & $0.28[0.04-2.07]$ & 0.214 & & \\
\hline No & 1 (reference) & & & \\
\hline \multicolumn{5}{|l|}{ Comorbidities $^{a}$} \\
\hline None & 1 (reference) & & & \\
\hline Mild & $1.05[0.42-2.63]$ & 0.923 & & \\
\hline Moderate & $0.75[0.23-2.42]$ & 0.629 & & \\
\hline Severe & $1.29[0.43-3.84]$ & 0.647 & & \\
\hline Tumour diameter & & $0.030^{b}$ & & \\
\hline$<20 \mathrm{~mm}$ & 1 (reference) & & 1 (reference) & \\
\hline $20-39 \mathrm{~mm}$ & $3.28[1.29-8.29]$ & 0.012 & $0.91[0.19-4.44]$ & 0.906 \\
\hline$\geq 40 \mathrm{~mm}$ & $2.42[0.56-10.37]$ & 0.235 & $1.25[0.18-8.84]$ & 0.822 \\
\hline \multicolumn{2}{|c|}{ Tumour differentiation } & $0.003^{b}$ & & \\
\hline Well & 1 (reference) & & 1 (reference) & \\
\hline Moderate & $1.28[0.56-2.94]$ & 0.563 & $2.27[0.63-8.11]$ & 0.209 \\
\hline Poor & $5.39[1.95-14.90]$ & 0.001 & $6.71[1.28-35.21]$ & 0.024 \\
\hline \multicolumn{5}{|l|}{ Invasion depth } \\
\hline$<2 \mathrm{~mm}$ & 1 (reference) & & 1 (reference) & \\
\hline $2-6 \mathrm{~mm}$ & $5.27[1.77-15.68]$ & 0.003 & $1.79[0.44-7.33]$ & 0.416 \\
\hline$>6 \mathrm{~mm}$ & $7.90[2.23-28.02]$ & 0.001 & $1.75[0.24-13.03]$ & 0.583 \\
\hline \multicolumn{5}{|c|}{ Perineural invasion } \\
\hline Yes & $5.58[2.35-12.34]$ & $<0.001$ & $1.90[0.39-9.15]$ & 0.426 \\
\hline No & 1 (reference) & & 1 (reference) & \\
\hline \multicolumn{5}{|c|}{ Vascular invasion } \\
\hline Yes & $4.44[1.03-19.06]$ & 0.045 & $2.18[0.37-12.72]$ & 0.386 \\
\hline No & 1 (reference) & & & \\
\hline \multicolumn{5}{|l|}{ Surgical margin } \\
\hline$<2 \mathrm{~mm}$ & 1 (reference) & & 1 (reference) & \\
\hline$\geq 2 \mathrm{~mm}$ & $0.07[0.02-0.30]$ & $<0.001$ & $0.11[0.02-0.50]$ & 0.004 \\
\hline
\end{tabular}

${ }^{\mathrm{a} C}$ Comorbidities were indexed by the Adult Comorbidity Evaluation-27 (ACE-27). ${ }^{\mathrm{b}} p$-value calculated by Wald test.

95\% CI: 95\% confidence interval; POD: progression of disease, comprising local recurrence, nodal metastasis and distant metastasis; SHR: subhazard ratio. Significant $p$-values are shown in bold. 
Table IV. Univariable and multivariable competing risk analysis for POD within 60 months in the patient group aged $\geq 75(n=356)$

\begin{tabular}{|c|c|c|c|c|}
\hline \multirow[b]{2}{*}{ Characteristics } & \multicolumn{2}{|l|}{ Univariable model } & \multicolumn{2}{|l|}{ Multivariable model } \\
\hline & SHR $[95 \% \mathrm{CI}]$ & $p$-value & SHR $[95 \% \mathrm{CI}]$ & $p$-value \\
\hline \multicolumn{5}{|l|}{ Sex } \\
\hline Men & 1 (reference) & & & \\
\hline Women & $0.72[0.39-1.33]$ & 0.296 & & \\
\hline \multicolumn{5}{|c|}{ Immunosuppression } \\
\hline Yes & $0.93[0.34-2.51]$ & 0.884 & & \\
\hline No & 1 (reference) & & & \\
\hline \multicolumn{5}{|l|}{ Comorbidities $^{a}$} \\
\hline None & 1 (reference) & & & \\
\hline Mild & $0.58[0.24-1.43]$ & 0.239 & & \\
\hline Moderate & $0.93[0.42-2.06]$ & 0.867 & & \\
\hline Severe & $1.38[0.55-3.46]$ & 0.498 & & \\
\hline \multicolumn{5}{|c|}{ Tumour diameter } \\
\hline$<20 \mathrm{~mm}$ & 1 (reference) & & 1 (reference) & \\
\hline 20-39 mm & $2.77[1.54-4.99]$ & 0.001 & $1.16[0.51-2.65]$ & 0.721 \\
\hline$\geq 40 \mathrm{~mm}$ & $4.17[1.79-9.72]$ & 0.001 & $2.90[1.08-7.76]$ & 0.034 \\
\hline \multicolumn{5}{|c|}{ Tumour differentiation } \\
\hline Well & 1 (reference) & & 1 (reference) & \\
\hline Moderate & $2.50[1.23-5.11]$ & 0.012 & $3.38[1.34-8.57]$ & 0.010 \\
\hline Poor & $5.28[2.28-12.21]$ & $<0.001$ & $6.72[2.39-18.92]$ & $<0.001$ \\
\hline \multicolumn{5}{|l|}{ Invasion depth } \\
\hline$<2 \mathrm{~mm}$ & 1 (reference) & & 1 (reference) & \\
\hline $2-6 \mathrm{~mm}$ & $3.31[1.46-7.49]$ & 0.004 & $3.22[1.11-9.35]$ & 0.032 \\
\hline$>6 \mathrm{~mm}$ & $9.25[3.82-22.43]$ & $<0.001$ & $7.39[2.16-25.25]$ & 0.001 \\
\hline \multicolumn{5}{|c|}{ Perineural invasion } \\
\hline Yes & $3.13[1.66-5.91]$ & $<0.001$ & $1.31[0.60-2.85]$ & 0.501 \\
\hline No & 1 (reference) & & 1 (reference) & \\
\hline \multicolumn{5}{|l|}{ Vascular invasion } \\
\hline Yes & $1.65[0.38-7.18]$ & 0.504 & & \\
\hline No & 1 (reference) & & & \\
\hline \multicolumn{5}{|l|}{ Surgical margin } \\
\hline$<2 \mathrm{~mm}$ & 1 (reference) & & 1 (reference) & \\
\hline$\geq 2 \mathrm{~mm}$ & $0.44[0.23-0.85]$ & 0.014 & $0.79[0.41-1.52]$ & 0.472 \\
\hline
\end{tabular}

${ }^{\mathrm{a} C}$ Comorbidities were indexed by the Adult Comorbidity Evaluation-27 (ACE-27). 95\% CI: 95\% confidence interval; POD: progression of disease, comprising local recurrence, nodal metastasis and distant metastasis; SHR: subhazard ratio. Significant $p$-values are shown in bold.

\section{DISCUSSION}

This large retrospective study observed more high-risk tumour characteristics in elderly patients. Furthermore, POD was observed more often in the elderly group, but the multivariable competing risk analysis showed that higher age itself was not an independent risk factor for POD. When analysing both age groups separately, poor differentiation grade was an independent risk factor in both groups, while a closer surgical margin was only statistically significant in patients under 75 years old, and moderate differentiation grade, tumour diameter $\geq 40 \mathrm{~mm}$ and invasion depth $\geq 2 \mathrm{~mm}$ were risk factors for patients 75 years old or older.

Studies comparing tumour characteristics of different age groups are limited. The results of the current study confirm an increase in the number of patients with cSC$\mathrm{CHN}$ over time and with age (19). Larger tumours were observed in elderly patients, in line with earlier studies $(15,20)$. The observed age-specific difference in tumour localization, with tumours in elderly patients arising more often on the temples, ears and scalp, and tumours in younger patients arising more often on the nose and vermillion, has not been found previously (20). A closer surgical margin was more common in the elderly group, as reported previously (21).

The current results show differences in tumour characteristics and oncological progression in elderly patients compared with their younger counterparts. This difference could be explained by a diagnostic delay leading to more advanced tumours, or it could indicate a difference in pathogenesis, which deserves further tumour biological and clinical research. The observed difference in tumour diameter, differentiation grade, invasion depth, and metastasis, to the disadvantage of the elderly patients, might indicate that cSCCHNs in elderly patients have a different tumour biology for oncological progression compared with younger patients. Since cSCC development and progression is more common in immunosuppressed patients, immunological senescence could play a role, leading to more aggressive tumours in elderly patients $(22,23)$. The role of the ageing immune microenvironment in cSCC has not been studied, but is described for other tumour types. Age-related cellular changes in the microenvironment may stimulate slowgrowing tumour cells to transform into aggressive and metastatic disease. In younger patients fibroblasts are providing a growth-restrictive environment for malignant cells through secretion of cytokines, growth factors and other proteins. Effector immune cells are cytotoxic towards malignant cells in healthy tissue. With age, the renewal rate of healthy fibroblast decreases, and immunosenescence leads to a decreased immune cell function. This might enable malignant cells to grow and multiply (24). A study in elderly patients with colorectal cancer shows that a high percentage of senescent cytotoxic $\mathrm{T}$ cells negatively impacts disease outcome (25). In patients with breast cancer, age-related differences in tumour immune response were described, with decreased lymphocytic infiltration in the older group (26). Another possible explanations for more frequent tumour progression in elderly patients related to tumour biology could be the metabolic alterations that occur with age and decreasing telomere length (27-31). The observed larger tumour diameter, deeper invasion and more frequent tumour progression in elderly patients might also be a result of patient or physician delay. Treatment delay is described in the literature to lead to larger cSCCs $(32,33)$. Moreover, elderly patients were found to be more likely to wait to seek care compared with younger patients (34).

Multiple studies assessed age as a possible risk factor for POD; however, none of these studies performed a competing risk analysis to take into account the higher age of cSCC patients. A retrospective study in 6,164 patients with 8,997 cSCCs (median age 74, range 21-108 years) found that age was not an independent risk factor for metastasis (35). Another retrospective study in 43 patients (mean age 74.7, standard deviation 10.2 years) with advanced cSCCHN (AJCC 8 T3/T4) found that age 
did not affect observed survival or recurrence rate (36). Kounoike et al. (21) did not find a significant difference in rates of recurrence and nodal metastasis between younger $(<85$ years) and elderly patients ( $\geq 85$ years). A systematic review and meta-analysis with 21 included articles found age to be a significant risk factor for overall survival, but not for locoregional control (37). Summarizing, in the literature age itself is found not to be an independent risk factor for POD in patients with cSCC.

Using a competing risk analysis to account for the risk of dying in an ageing population, we showed that age was not an independent risk factor for POD. However, POD was significantly more common in the elderly patient group with the competing risk of death taken into account. Furthermore, independent risk factors are identified for the separate age groups, although these findings should be confirmed by larger studies. Interestingly, a larger tumour size did not seem to be prognostic for disease progression in younger patients. A possible explanation could be the small sample size of only 12 patients in the younger group with a tumour diameter $\geq 4 \mathrm{~cm}$. Furthermore, most elderly patients with large tumours were treated with surgical monotherapy, while the younger patients with large tumours were mostly treated with surgery and postoperative radiotherapy. This could be related to patient compliance: patients with endometrial cancer or breast cancer declining postoperative radiotherapy were more likely to be older $(38,39)$.

In daily clinical practice, knowledge about age-dependent tumour biology could lead to a more personalized treatment or follow-up schedule. A possible adaptation could be a more intensive follow-up schedule in elderly patients with independent risk factors for POD, regardless of tumour stage. Elderly patients have a higher chance to develop postoperative complications (40), larger defects after surgery and more wound-healing disorders (15). Our analyses showed surgical margin not to be an independent risk factor for POD in elderly patients. If this result is confirmed by future studies, then a wait-and-see policy after close surgical margins with more intensive follow-up instead of re-excision might be justifiable for elderly patients; however, randomized controlled trails are needed to give such recommendations. In contrast, frail elderly patients might encounter difficulties with an intensive follow-up schedule, due to mobility problems. In these cases a re-excision might be preferable to avoid frequent hospital visits. Should diagnostic delay be the main reason for the differences in tumour characteristics between younger and elderly patients, raising consciousness on skin cancer recognition amongst the elderly patients, as well as amongst (para) medics treating elderly patients might be important to improve disease outcomes.

A limitation of this study is the monocentre setup in a tertiary centre, which might lead to a selection of patients with more complex tumours. Furthermore, due to its retrospective nature, diagnostic delay could not be assessed in this study. The major strengths of this study are that all missing histopathological data were reassessed by a dermatopathologist, and the use of competing risk analyses, which is a novelty in this research area.

In conclusion, tumour characteristics in elderly and younger patients with cSCCHN differ, with more highrisk characteristics in elderly patients. POD is significantly more common in elderly patients, and different independent risk factors are identified for younger and elderly patients. This suggests that a more personalized treatment and follow-up with attention to the age of the patient can be beneficial. Patients might rather benefit from management based on the age-specific risk factors for progression and performance score, than treatment based purely on tumour stage. Further research is necessary to confirm these results and give clear recommendations on age-specific tailored treatment and follow-up in patients with cSCCHN.

\section{ACKNOWLEDGEMENTS}

The authors wish to acknowledge Marieke Louwman, $\mathrm{PhD}$, and Myrna Bakker, MD, for their contributions to this project.

This study was reviewed and approved by the Institutional Review Board of the University Medical Center Groningen. This research received a grant from the University Medical Center Groningen in the context of a Healthy Ageing Project.

The authors have no conflicts of interest to declare.

\section{REFERENCES}

1. Hollestein LM, de Vries E, Nijsten T. Trends of cutaneous squamous cell carcinoma in the Netherlands: increased incidence rates, but stable relative survival and mortality 1989-2008. Eur J Cancer 2012; 48: 2046-2053.

2. Holterhues C, Vries E, Louwman MW, Koljenovic S, Nijsten T. Incidence and trends of cutaneous malignancies in the Netherlands, 1989-2005. J Invest Dermatol 2010; 130: 1807-1812.

3. Karia PS, Han J, Schmults CD. Cutaneous squamous cell carcinoma: estimated incidence of disease, nodal metastasis, and deaths from disease in the United States, 2012. J Am Acad Dermatol 2013; 68: 957-966.

4. Kallini JR, Hamed N, Khachemoune A. Squamous cell carcinoma of the skin: epidemiology, classification, management, and novel trends. Int J Dermatol 2015; 54: 130-140.

5. Fears TR, Scotto J. Estimating increases in skin cancer morbidity due to increases in ultraviolet radiation exposure. Cancer Invest 1983; 1: 119-126.

6. Stang A, Khil L, Kajüter H, Pandeya N, Schmults CD, Ruiz $E S$, et al. Incidence and mortality for cutaneous squamous cell carcinoma: comparison across three continents. J Eur Acad Dermatol Venereol 2019; 33: 6-10.

7. Lomas A, Leonardi-Bee J, Bath-Hextall F. A systematic review of worldwide incidence of nonmelanoma skin cancer. $\mathrm{Br}$ J Dermatol 2012; 166: 1069-1080.

8. (NVDV) NV voor D en V. Guideline squamous cell carcinoma of the skin. 2018;

9. Stratigos AJ, Garbe C, Dessinioti C, Lebbe C, Bataille V, Bastholt $L$, et al. European interdisciplinary guideline on invasive squamous cell carcinoma of the skin: Part 1 . epidemiology, diagnostics and prevention. Eur J Cancer 2020; 128: 60-82.

10. Alam M, Ratner D. Cutaneous squamous-cell carcinoma. N Engl J Med 2001; 344: 975-983. 
11. Brantsch KD, Meisner C, Schonfisch B, Trilling B, WehnerCaroli J, Rocken M, et al. Analysis of risk factors determining prognosis of cutaneous squamous-cell carcinoma: a prospective study. Lancet Oncol 2008; 9: 713-720.

12. Moore BA, Weber RS, Prieto V, El-Naggar A, Holsinger FC, Zhou $X$, et al. Lymph node metastases from cutaneous squamous cell carcinoma of the head and neck. Laryngoscope 2005; 115: 1561-1567.

13. Schmidt C, Martin JM, Khoo E, Plank A, Grigg R. Outcomes of nodal metastatic cutaneous squamous cell carcinoma of the head and neck treated in a regional center. Head Neck 2015; 37: 1808-1815.

14. Haisma MS, Bras L, Aghdam MA, Terra JB, Plaat BEC, Rácz $E$, et al. Effect of patient characteristics on treatment decisions regarding keratinocyte carcinoma in elderly patients: a review of the current literature. Acta Derm Venereol 2020: 100: adv00189.

15. Leus AJG, Frie M, Haisma MS, Terra JB, Plaat BEC, Steenbakkers RJHM, et al. Treatment of keratinocyte carcinoma in elderly patients - a review of the current literature. J Eur Acad Dermatol Venereol 2020; 34: 1932-1943.

16. de Vries J, Heirman AN, Bras L, Plaat BEC, Rácz E, van Kester MS, et al. Geriatric assessment of patients treated for cutaneous head and neck malignancies in a tertiary referral center: predictors of postoperative complications. Eur J Surg Oncol 2020; 46: 123-130.

17. Website of the National Institute on Ageing. [cited $2019 \mathrm{Dec}$ 19]. Available from: www.nia.nih.gov.

18. Karia PS, Morgan FC, Califano JA, Schmults CD. comparison of tumor classifications for cutaneous squamous cell carcinoma of the head and neck in the 7th vs 8th Edition of the AJCC Cancer Staging Manual. JAMA Dermatol 2018; 154: 175-181.

19. Green AC, Olsen CM. Cutaneous squamous cell carcinoma: an epidemiological review. Br J Dermatol 2017; 177: 373-381.

20. Wiser I, Scope A, Azriel D, Zloczower E, Carmel NN, Shalom A. Head and neck cutaneous squamous cell carcinoma clinicopathological risk factors according to age and gender: a population-based study. Isr Med Assoc J 2016; 18: 275-278.

21. Kounoike N, Akimoto M, Nemoto M, Ishikawa S, Sugimoto T, Takeda A. Surgical treatment of cutaneous squamous cell carcinoma in Japanese patients aged 85 years and older compared with those below 85 years. Kitasato Med J 2015; 45: $118-123$.

22. Lian J, Yue Y, Yu W, Zhang Y. Immunosenescence: a key player in cancer development. J Hematol Oncol 2020; 13: 151.

23. De Maeyer RPH, Chambers ES. The impact of ageing on monocytes and macrophages. Immunol Lett $2021 ; 230$ : 1-10.

24. Fane M, Weeraratna AT. How the ageing microenvironment influences tumour progression. Nat Rev Cancer 2020; 20: 89-106.

25. Giunco S, Petrara MR, Bergamo F, Del Bianco P, Zanchetta $M$, Carmona $F$, et al. Immune senescence and immune activation in elderly colorectal cancer patients. Aging 2019; 11: 3864-3875.

26. Berben L, Floris G, Kenis C, Dalmasso B, Smeets A, Vos H, et al. Age-related remodelling of the blood immunological portrait and the local tumor immune response in patients with Iuminal breast cancer. Clin Transl Immunol 2020; 9: e1184.

27. Gomes AP, Ilter D, Low V, Endress JE, Fernández-García J, Rosenzweig $A$, et al. Age-induced accumulation of methylmalonic acid promotes tumour progression. Nature 2020; 585: 283-287.

28. Serrano M, Blasco MA. Cancer and ageing: convergent and divergent mechanisms. Nat Rev Mol Cell Biol 2007; 8: 715-722.

29. Ma H, Zhou Z, Wei S, Liu Z, Pooley KA, Dunning AM, et al. Shortened telomere length is associated with increased risk of cancer: a meta-analysis. PLoS One 2011; 6: 1-9.

30. Rizvi S, Raza ST, Mahdi F. Telomere length variations in aging and age-related diseases. Curr Aging Sci 2014; 7: 161-167.

31. Anic GM, Sondak VK, Messina JL, Fenske NA, Zager JS, Cherpelis BS, et al. Telomere length and risk of melanoma, squamous cell carcinoma, and basal cell carcinoma. Cancer Epidemiol 2013; 37: 434-439.

32. Eide MJ, Weinstock MA, Dufresne Jr RG, Neelagaru S, Risica $P$, Burkholder GJ, et al. Relationship of treatment delay with surgical defect size from keratinocyte carcinoma (basal cell carcinoma and squamous cell carcinoma of the skin). J Invest Dermatol 2005; 124: 308-314.

33. Renzi C, Mastroeni S, Passarelli F, Mannooranparampil TJ, Caggiati A, Potenza C, et al. Factors associated with large cutaneous squamous cell carcinomas. J Am Acad Dermatol 2010; 63: 404-411.

34. Alam M, Goldberg LH, Silapunt S, Gardner ES, Strom SS, Rademaker AW, et al. Delayed treatment and continued growth of nonmelanoma skin cancer. J Am Acad Dermatol 2011; 64: 839-848.

35. Brougham ND, Dennett ER, Cameron R, Tan ST. The incidence of metastasis from cutaneous squamous cell carcinoma and the impact of its risk factors. J Surg Oncol 2012; 106: 811-815.

36. Sullivan CB, Andresen NS, Kendell N, Al-Qurayshi Z, Pagedar NA. Survival outcomes for advanced cutaneous squamous cell carcinoma of the head and neck. Ann Otol Rhinol Laryngol 2019; 128: 949-955.

37. Sahovaler A, Krishnan RJ, Yeh DH, Zhou Q, Palma D, Fung K, et al. Outcomes of cutaneous squamous cell carcinoma in the head and neck region with regional lymph node metastasis: a systematic review and meta-analysis. JAMA Otolaryngol Head Neck Surg 2019; 145: 352-360.

38. Matsuo K, Machida H, Ragab OM, Garcia-Sayre J, Yessaian AA, Roman LD. Patient compliance for postoperative radiotherapy and survival outcome of women with stage I endometrioid endometrial cancer. J Surg Oncol 2017; 116: 482-491.

39. Badakhshi H, Gruen A, Sehouli J, Budach V, Boehmer D. The impact of patient compliance with adjuvant radiotherapy: a comprehensive cohort study. Cancer Med 2013; 2: 712-717.

40. Story DA. Postoperative complications in elderly patients and their significance for long-term prognosis. Curr Opin Anaesthesiol 2008; 21: 375-379. 